OPEN ACCESS

Edited by:

Stefano Farris,

University of Milan, Italy

Reviewed by:

Zhibao Huo,

Shanghai Jiao Tong University, China Masoud Ghaani,

University of Milan, Italy

${ }^{*}$ Correspondence:

Debora Puglia debora.puglia@unipg.it

Specialty section: This article was submitted to Chemical Engineering, a section of the journal Frontiers in Chemistry

Received: 29 October 2018 Accepted: 04 March 2019 Published: 26 March 2019

Citation:

Iglesias Montes ML, Luzi F, Dominici F Torre L, Cyras VP, Manfredi LB and Puglia D (2019) Design and Characterization of PLA Bilayer Films

Containing Lignin and Cellulose Nanostructures in Combination With Umbelliferone as Active Ingredient.

Front. Chem. 7:157.

doi: 10.3389/fchem.2019.00157

\section{Design and Characterization of PLA Bilayer Films Containing Lignin and Cellulose Nanostructures in Combination With Umbelliferone as Active Ingredient}

\author{
Magdalena L. Iglesias Montes ${ }^{1}$, Francesca Luzi ${ }^{2}$, Franco Dominici ${ }^{2}$, Luigi Torre ${ }^{2}$, \\ Viviana P. Cyras ${ }^{1}$, Liliana B. Manfredi ${ }^{1}$ and Debora Puglia ${ }^{2 *}$ \\ ${ }^{1}$ Facultad de Ingeniería, Instituto de Investigaciones en Ciencia y Tecnología de Materiales, Universidad Nacional de Mar del \\ Plata, Mar del Plata, Argentina, ${ }^{2}$ Civil and Environmental Engineering Department, UdR INSTM, University of Perugia, Terni, \\ Italy
}

Poly (lactic acid) (PLA) bilayer films, containing cellulose nanocrystals (CNC) or lignin nanoparticles (LNP) and Umbelliferone (UMB) were extruded and successfully layered by thermo-compression starting from monolayer films. Lignocellulosic nanostructures were used in PLA based film as nanofillers at $3 \mathrm{wt} . \%$, while UMB was used as active ingredient (Al) at $15 \mathrm{wt} . \%$. The effects of processing techniques, presence, typology and content of lignocellulosic nanoparticles have been analyzed and thermal, morphological, mechanical and optical characterization of PLA nanocomposites have been made. Furthermore, X-ray diffraction (XRD) and Fourier Transform Infrared spectroscopy (FTIR) studies evaluated the presence of nanofillers and Al at chemical level. Bilayer formulations showed a good interfacial adhesion and improved stress at break with respect of PLA monolayers, although they were less stretchable and transparent. Data obtained from thermal, colorimetric and transparency investigations underlined that the presence of lignocellulosic nanofillers and Al in PLA monolayer and bilayer films induced relevant alterations in terms of overall color properties and thermal stability, while antioxidant activity of umbelliferone was enhanced by the addition of lignin in produced materials.

\footnotetext{
Keywords: poly (lactic acid), cellulose nanocrystals, lignin nanoparticles, umbelliferone, melt-compounding techniques, mechanical properties, food packaging
}

\section{INTRODUCTION}

The continue demand of semi prepared natural and fresh food products with high nutritional value have promoted the current trend in food packaging application to develop new systems to improve the shelf-life of packaged foods (Fabra et al., 2016; Luzi et al., 2018b). Specifically, the packages contain, cover and protect the foodstuffs from the external attacks as light irradiation, external contaminations, and oxidation induced by the contact with the air (Lee et al., 2015; Domínguez et al., 2018; Luzi et al., 2018a). The shelf-life of certain foods may be significantly limited if no some chemical ingredients are added. The meat is one of the main perishable food characterized by the presence of fat and a high content of unsaturated fatty acids subjected to lipid oxidation causing the quality deterioration in meat and meat based products and consequentially to deterioration process 
was observed also the microbial growth (Yang et al., 2016a; Banerjee et al., 2017; Domínguez et al., 2018).

In this scenario, several strategies were adopted to improve the quality and the safety of packaged foods, to reduce the environmental burden due to the disposal of spoiled foods, to increase the quantity of food available for human utilization and finally to reduce the economic impact caused by the deteriorations of foods (Yang et al., 2016a). The different measures adopted on food preservation/protection play a great function. Food conservation consists in preventing all aspects concerned in food contamination and deterioration which are the main problem of loss in safety of food and nutritional value. The most important are the oxidative processes, which are liable for the modification of flavor, the degradation of vitamins, and the deterioration of foodstuffs such as the browning of meat, fruits and vegetables. Active packages symbolize some interesting possibilities spanning through the entire food chain from producers and distributors to consumers (Lee et al., 2015).

Recent research studies proposed some different approaches to modulate and to enhance the shelf-life of foods: incorporation of active ingredients/agents into packaging based systems and the development of bilayer polymeric based systems to modulate the exchange of gas flow between the internal and external parts of the packaging (Muller et al., 2017). Recently, several phenolic compounds and natural extracts as hydroxytyrosol, rosmery, carvacrol, catechin, gallic acid, etc. (Cerruti et al., 2009; Castro López et al., 2013; Arrieta et al., 2016; Fortunati et al., 2016a; Luzi et al., 2017, 2018a; Piñeros-Hernandez et al., 2017) have been studied in combination with polymeric materials to improve the active properties of neat polymers of great significance in the food sector.

Antioxidant active and smart packaging seeks to stop or reduce the oxidation of different food components, principally, proteins and lipids, which lead to the deterioration of physical and organoleptic properties (such as color and flavor). The realization of active polymeric based materials is centered on the incorporation of antioxidant compounds into the packages and their further migration to the food (Fabra et al., 2016). Polymers, and specifically biodegradable polymers, are the main preferred materials for food packaging application. In fact, green based polymeric systems represent an alternative to develop novel eco-friendly systems that can reduce the amount of wastes in landfills respect to petroleum based polymers. Respect to traditional polymers green based systems can also minimize the greenhouse gas emissions during the realization and the end-of-life disposal (Peelman et al., 2013).

In spite that usually green polymers have lower mechanical performance and poorer barrier properties than traditional ones, they are feasible materials for active packaging due to their intrinsic characteristics. They can be good carrier substrates of active principles because of their adaptability to controlled release and also they can be combined through the realization of polymeric blends or multilayer formulations in order to optimize the application (Martínez-Abad et al., 2014). In this context, the development of bilayer films represent a strategic alternative to improve the barrier essential in the fresh food package to guarantee the shelf-life of the products and the mechanical properties of biobased systems (Muller et al., 2017).

Poly(lactic acid) (PLA) is a thermoplastic linear aliphatic polyester, obtained from renewable resources, compostable and biodegradable (Chaiwutthinan et al., 2015). PLA is accepted by US Food and Drug Administration (FDA) as a food contact matter, non-toxic or carcinogenetic, easy to process, transparent, economically feasible, and it is utilized to realize packaging for short shelf-life uses (Arrieta et al., 2013). Unluckily, as described in general for biodegradable polymers also PLA is characterized by some drawbacks when compared with petroleum base matrices utilized in food packaging sector.

Nanocomposites represent as a valid strategy to modulate the moderate characteristics of biodegradable polymers. Recently, lignin nanoparticles (LNPs) and cellulose nanocrystals (CNC) have been used as nanoreinforcements to enhance the characteristics of biobased polymeric systems for food packaging applications (Fortunati et al., 2013, 2016b; El-Wakil et al., 2015).

Lignin components provide specific food antioxidant properties (Domenek et al., 2013; Yang et al., 2016b) and UV stabilization effect (Chung et al., 2013). It has been established that the radical scavenging activity is related to particle size and that the antioxidant effect increase decreasing the dimensions of fillers (Ge et al., 2014). Moreover, enhanced thermal and mechanical characteristics of different polymer matrices were found (Nair et al., 2014). Additionally, LNPs is a promising green agent useful against dangerous bacteria and microorganisms, its intrinsic biocide effect allows to decrease the environmental problems associated to the utilize of silver nanoparticles (Richter et al., 2015; Yang et al., 2016b).

With the same aim, cellulose nanocrystals (CNC), which are characterized by low density, high biocompatibility and stiffness (Fernandes et al., 2013), contribute to increase the overall thermomechanical performance of polymeric materials, due to the synergic interactions of crystal nucleation, tortuosity and chain immobilization (Pracella et al., 2014; Kamal and Khoshkava, 2015). Moreover, active ingredients such as umbelliferone (7-hydroxycoumarin), a natural phenolic extract extensively spread in plants of the coumarin family with antioxidant and antimicrobial effects (Mazimba, 2017; Luzi et al., 2018b), could improve the antioxidant response of polymeric films even in a multilayer approach. While the use of natural, non-toxic antioxidants such as ferulic acid or $\alpha$-tocopherol to extend the food shelf life has been investigated, limited information exists about the influence of umbelliferone on films structure and physicochemical properties in packaging application. The successful use of UMB in $\mathrm{EVOH}$ matrix has been already tested and compared with gallic acid effectiveness in Luzi et al. (2018b). In addition, on the basis of available relevant results on UMB use in medicine (umbelliferone has been demonstrated to have biological activity as an antibacterial, anti-inflammatory, antirheumatic, and immunomodulatory agent), we planned to comprehensively verify its possible use in a sector having similar requirements, to demonstrate enhanced antibacterial and antioxidant properties when combined with lignin based nanoparticles. 
The aim of this work is therefore the design, realization, and characterization of poly (lactic acid) (PLA) based bilayer films for food packaging applications. PLA monolayer films containing cellulose nanocrystals (CNC) or lignin nanoparticles (LNP) and Umbelliferone (UMB) were extruded and successfully layered by thermo-compression. The effect of the different nanoparticles and the active ingredient (UMB) on the properties of the bilayer system was studied. Emphasis was placed on the determination of antioxidant and light transmission results according to the proposed use of the materials as packaging.

\section{MATERIALS AND METHODS}

\section{Materials}

Poly(lactic acid) (PLA) 3051D, with a specific gravity of $1.25 \mathrm{~g}$ $\mathrm{cm}^{-3}$, a molecular weight $\left(M_{n}\right)$ of ca. $1.42 \times 10^{4} \mathrm{~g} \mathrm{~mol}^{-1}$, and a melt flow index (MFI) of $7.75 \mathrm{~g} 10 \mathrm{~min}^{-1}\left(210^{\circ} \mathrm{C}, 2.16 \mathrm{~kg}\right)$ was purchased by Nature Works ${ }^{\circledR}$, USA. Pristine lignin was supplied by CRB (Centro Ricerca Biomasse, University of Perugia) and lignin nanoparticles (LNP) were synthesized as previously reported (Yang et al., 2015a). Microcrystalline cellulose (MCC, dimensions of $10-15 \mu \mathrm{m})$, utilized as cellulose nanocrystals precursor during the hydrolysis process, was purchased by Sigma-Aldrich ${ }^{\circledR}$. Cellulose nanocrystals (CNC) were synthesized as previously reported (Fortunati et al., 2014). Umbelliferone (UMB) and all the chemical reagents were purchased from Sigma Aldrich $\AA$ and used as received.

\section{Preparation of PLA Nanocomposite Films}

PLA pellets, CNC and LNP were previously dried in an air circulating oven at $50^{\circ} \mathrm{C}$ overnight in order to eliminate moisture traces. Neat PLA, two different formulations of PLA nanocomposite (PLA_3\%CNC, PLA_3\%LNP), and a PLA active film (PLA_15\%UMB) were realized in a twin screw microextruder (DSM Explore 5\&15 CC Micro Compounder) taking as a reference sample neat PLA. The processing parameters were optimized for each formulation. During the mixing, the screw speed was set at $100 \mathrm{rpm}$ through $3 \mathrm{~min}$ (with nano-compound it was $2 \mathrm{~min}$ for the neat PLA and $1 \mathrm{~min}$ for de nano-component), with a temperature profile of $180-190-200^{\circ} \mathrm{C}$ throughout the three zones and a dye temperature of $195^{\circ} \mathrm{C}$. The films obtained following this process have a nominal thickness between 80 and $85 \mu \mathrm{m}$.

\section{Preparation of Bilayer Films}

In order to obtain bilayer films, the different PLA monolayers were assembled and compressed at $155^{\circ} \mathrm{C}$ for $1 \mathrm{~min}$ at a pressure of 25 bar followed by a cooling cycle. Six kinds of films were obtained: pure polymer bilayer film (PLA/PLA), as a control, and films with nano and active compounds (PLA/PLA_3\%CNC, PLA/PLA_3\%LNP, PLA/PLA_15\%UMB, PLA_3\%CNC/PLA_15\%UMB, PLA_3\%LNP/PLA_15\%UMB). CNC, LNP and UMB have been selected according to previous results obtained by the authors on separated or combined use of CNC and LNP in polylactic acid (Yang et al., 2016b), while the amount of UMB was selected on the basis of dispersability results and its effect of transparency and antibacterial response when introduced in polymeric film formulations (Luzi et al., 2018b).

\section{Film Characterization}

\section{Structural Characterization}

$\mathrm{X}$-ray diffraction (XRD) analysis of the samples was obtained with an X-Pert pro diffractometer with $\mathrm{CuK} \alpha$ radiation $(\lambda=1.54$ $\AA$ ), operating at $40 \mathrm{kV}$ and $40 \mathrm{~mA}$. The diffraction profile was detected from 4 to $60^{\circ}$ at a scanning rate of $2^{\circ} / \mathrm{min}$.

FT-IR measurements were performed at room temperature in reflection mode in attenuated total reflectance (ATR) using a Thermo Scientific Nicolet Instrument 6700. Spectra were acquired within 4,000-600 $\mathrm{cm}^{-1}$ region, using 32 scans overlapped and $4 \mathrm{~cm}^{-1}$ resolution.

The cross section micromorphology of the films was observed using a field emission scanning electron microscope (FESEM, Supra 25- Zeiss, Germany). Films were initially fractured in liquid nitrogen and gold coated with an Agar automatic sputter coated.

\section{Light Transmission and Color Properties}

The light transmission test were performed on film samples in the visible light region (400-700 $\mathrm{nm}$ ) using a spectrophotometer (CM-2300d Konica Minolta, Japan), while film color properties were evaluated by using the CIELAB color space by means MultiGloss 268, Minolta, Langenhagen, Germany. Color coordinates, $\mathrm{L}^{*}$ (lightness), $\mathrm{a}^{*}$ (red-green), and $\mathrm{b}^{*}$ (yellow- blue) were measured. The instrument was calibrated using a white standard tile. Average values of three different measurements at random positions over the film surfaces were obtained. Total color difference $\left(\Delta \mathrm{E}^{*}\right)$ was evaluated with respect to the white control as follow:

$$
\Delta E^{*}=\sqrt{\left(\Delta L^{*}\right)^{2}+\left(\Delta a^{*}\right)^{2}+\left(\Delta b^{*}\right)^{2}}
$$

Gloss value was also evaluated using a flat surface gloss meter at an incidence angle of $60^{\circ}$, according to the ASTM standard D523 (ASTM, 2018).

\section{Thermal Properties}

\section{Differential scanning calorimetry (DSC)}

DSC analysis was performed by using a TA Instruments DSC Q200 in modulated mode (TA Instruments Inc., USA) under nitrogen atmosphere. The scanning process covered from -25 to $210^{\circ} \mathrm{C}$, applying two heating and one cooling scan, at $10^{\circ} \mathrm{C} / \mathrm{min}$. Glass transition, crystallization and melting phenomena of film samples were defined from the first heating scan. Degree of crystallinity $(X c)$ was evaluated by using Equation (2):

$$
\chi_{C}=\left(\frac{\Delta H_{m}-\Delta H_{c c}}{w \cdot \Delta H_{m}^{0}}\right) \times 100
$$

where $\Delta H_{m}$ and $\Delta H_{c c}$ are the enthalpy of melting and cold crystallization peaks, respectively; $w$ is the weight fraction of PLA polymer in the sample and $\Delta H_{m}^{0}$ is the melting enthalpy of PLA $100 \%$ crystalline $(93 \mathrm{~J} / \mathrm{g}$ ) (Abdelwahab et al., 2012). 


\section{Thermogravimetric analysis (TGA)}

Dynamic thermal degradation was performed using a TG-50 Shimadzu, under nitrogen atmosphere. Temperature was raised from 25 to $800^{\circ}$, at a heating rate of $10^{\circ} \mathrm{C} / \mathrm{min}$. The initial degradation temperature $\left(T_{0}\right)$ was calculated at $5 \%$ mass loss, while temperatures at the maximum degradation rate $\left(T_{\max }\right)$ for each stage were determined from the first derivatives of the TGA curves (DTG).

\section{Mechanical Properties}

Tensile characteristics of different formulations were evaluated at room temperature using an universal testing machine, based on UNI ISO 527 standard (crosshead speed of $1 \mathrm{~mm} / \mathrm{min}$ ). Mechanical parameters, i.e., elastic modulus (EM), tensile strength (TS), and elongation at break $(\varepsilon)$, were obtained from the resulting stress-strain curves. Reported values were the average of at least five valid tests.

\section{Antioxidant Activity}

The antioxidant activity of films samples was evaluated using a spectroscopic method based on the disappearance of the absorption band at $517 \mathrm{~nm}$ of the free radical 2,2-diphenyl-1picrylhydrazyl (DPPH) (Sigma-Aldrich $\left.{ }^{\circledR}\right)$, upon reduction by an antiradical compound.

The radical scavenging activity was determined by using a spectroscopic method according to the method reported in literature by Byun et al. (2010). The different systems ( $0.1 \mathrm{~g})$ were cut into small pieces and immersed in $2 \mathrm{~mL}$ of methanol for $24 \mathrm{~h}$. An aliquot of methanol extract $(1 \mathrm{~mL})$ was uniformly mixed with $1 \mathrm{~mL}$ of DPPH in methanol $\left(50 \mathrm{mg} \mathrm{L}^{-1}\right)$. The mixture was allowed to stand at RT in the dark for $60 \mathrm{~min}$. The absorbance was measured at $517 \mathrm{~nm}$ using a UV spectrometer (Lambda 35). The DPPH mixture solution of methanol obtained from neat PLA systems was utilized as control. DPPH radical scavenging activity (RSA) was calculated according to the Equation (3):

$$
(R S A, \%)=\left[\frac{A_{\text {control }}-A_{\text {sample }}}{A_{\text {comtrol }}}\right] \times 100
$$

where $A_{\text {control }}$ is the absorbance of the control (methanol) at $t$ $=0$ min and $A_{\text {sample }}$ is the absorbance of tested sample after $1 \mathrm{~h}$ of incubation.

\section{RESULTS AND DISCUSSION \\ XRD Characterization}

In Figure 1, X-ray diffraction patterns of different components, monolayer (Figure 1A) and bilayer PLA films (Figure 1B) are reported. In order to study the effect of the different ingredients on the crystalline structure of the PLA, XRD traces for cellulose nanocrystals, lignin nanoparticles and umbelliferone have been also included. The crystalline structure of cellulose nanocrystals was characterized by four main reflection peaks located at $2 \theta=$ $15.08,16.38,22.58$, and 34.5 (Ludueña et al., 2015), while XRD pattern of lignin nanoparticles, that consists of phenylpropane unit forming a three dimensional polymer network without an ordered and regular super-molecular structure, shows a broad peak, indicating that the LNPs were only partially crystalline in nature (Gupta et al., 2014). Umbelliferone showed main peaks at $2 \theta=11.2,16.0,25.9$, and 28.1 (Liu et al., 2017).

In the case of PLA monolayers, it was observed that crystallization was not induced by the addition of any nanoadditive, since no additional peaks appeared in the spectra of the monolayers. Neat PLA presented a halo centered at $2 \theta$ $=16^{\circ}$, which is characteristic of amorphous scattering of PLA (Abdelwahab et al., 2012), as already observed by Gorrasi and Pantani (2013). The XRD profile was not modified in presence of CNC and LNP nanofillers, while main characteristic peaks of umbelliferone were detected in PLA_15UMB at 11.3, 16.1, and $28.2^{\circ}$.

No apparent change in crystallinity, as a result of the introduction of lignin and cellulose as nucleating agent, was evidenced in the X-ray diffractograms of PLA bilayers: a similar amorphous band as that identified in the PLA monolayer, regardless of the adhesion to the single or composite PLA layer, was detected, while the signal of umbelliferone, present in higher amount with respect of CNC and LNP, was more visible.

Actually, XRD patterns of PLA bilayers showed some dissimilarity with respect to monolayer PLA films in the case of PLA_3CNC/PLA_15UMB, highlighting the influence the different crystalline phases. Indeed, a new peak at $2 \theta=$ $19.2^{\circ}$ was recorded, revealing the presence of $\alpha^{\prime}$-form crystals (Kalish et al., 2011). Moreover, the diffraction shoulders located at 14.9 and $16.8^{\circ}$ may be owed to low crystallinity of the PLA and its imperfect crystals (Jia et al., 2017). These results suggest that the presence of cellulose nanocrystals and diffusion of UMB during thermo-compression slightly influenced the crystallization pattern of PLA due to the promotion of chain interactions with these compounds.

\section{FTIR Analysis}

FTIR analysis was performed on powders (Figure 2A), monolayer (Figure 2B), and bilayer films (Figure 2C) in order to identify the influence of the additives on the chemical structure of the PLA. The FT-IR spectrum of umbelliferone showed a sharp peak of $\mathrm{OH}$ group at $3,153 \mathrm{~cm}^{-1}$ (Ittadwar and Puranik, 2017), frequencies identified at 3,122 and $2,987 \mathrm{~cm}^{-1}$ are designated to $\mathrm{C}-\mathrm{H}$ stretching vibrations, single bonded carbonyl group vibrations at 1388, 1,345, and $1,233 \mathrm{~cm}^{-1}$, while frequencies at $1,578,1,454,1,446,1,409$, and $1,386 \mathrm{~cm}^{-1}$ have been designated to $\mathrm{C}-\mathrm{C}$ stretching vibrations (Rexali, 2007).

Lignin spectrum show complex bands and this is due to the variety of vibration mode of chemical bonds present in this biopolymer structure. The aromatic skeleton vibrations in lignin nanoparticles are assigned at $1,540 \mathrm{~cm}^{-1}(\mathrm{C}-\mathrm{C}$ stretching of aromatic skeletal around), $\mathrm{C}-\mathrm{H}$ stretching at $1,480 \mathrm{~cm}^{-1}$ and $\mathrm{CH}$ vibration of methyl group at $1,440 \mathrm{~cm}^{-1}$ (Yang et al., 2015b). CNC infrared spectrum was characterized by the presence of the absorption peaks around 3,330,2,897, 1,654, and $1,025 \mathrm{~cm}^{-1}$ related, respectively, to $\mathrm{O}-\mathrm{H}, \mathrm{C}-\mathrm{H}$ stretching, $\mathrm{C}-\mathrm{C}$ bending, and C-O stretching vibrations of cellulose (Bassett et al., 1963).

The main characteristic peaks of PLA were also identified in the spectra showed in Figure 2B. The main one at 1,750 

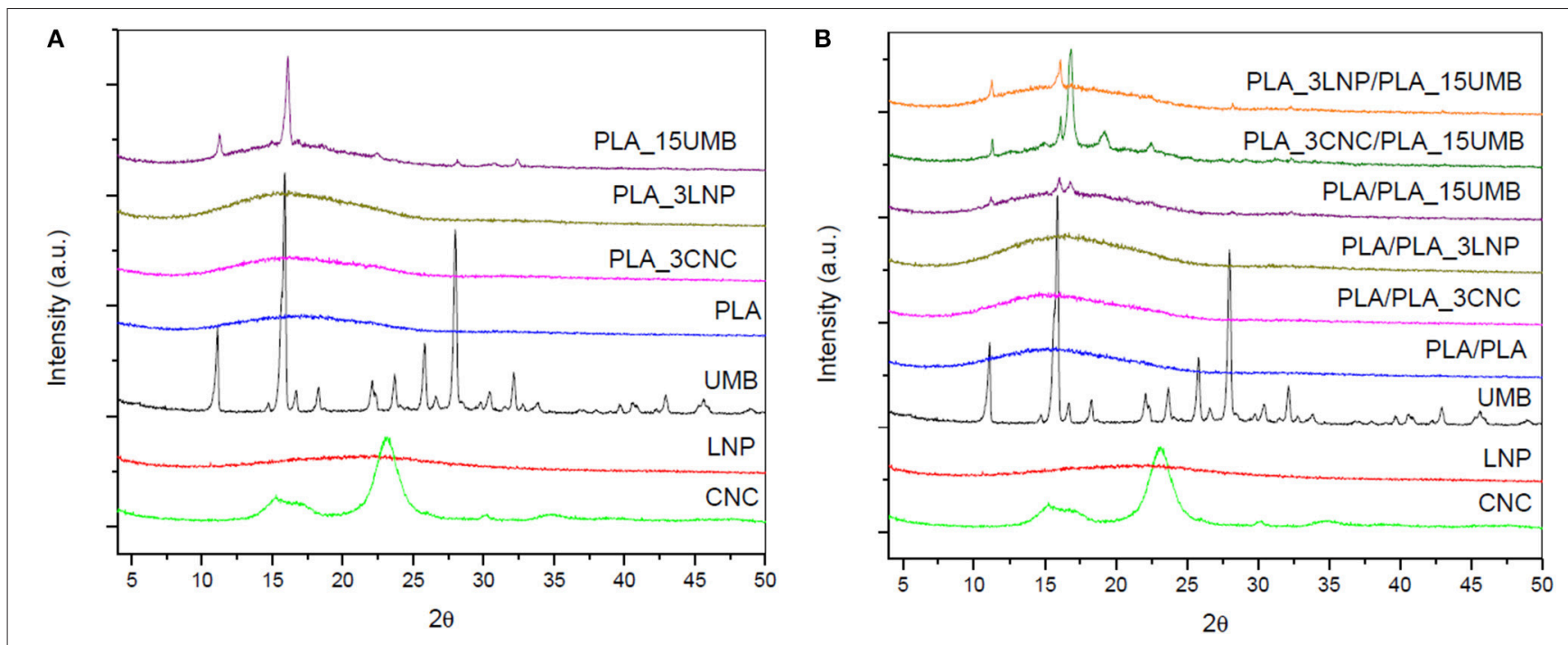

FIGURE 1 | XRD spectra of PLA and PLA nanocomposites (A) monolayer films; (B) bilayer films.

$\mathrm{cm}^{-1}$ corresponds to the $-\mathrm{C}=\mathrm{O}$ stretching vibration of the ester group and the peaks at 1,454 and $1,360 \mathrm{~cm}^{-1}$ are assigned to the asymmetric and symmetric $-\mathrm{CH}_{3}$ deformation vibrations, respectively. The $\mathrm{C}=\mathrm{O}$ bending appeared at $1,265 \mathrm{~cm}^{-1}$, the $\mathrm{C}-\mathrm{O}-\mathrm{C}$ - stretching of the ester groups at $1,182 \mathrm{~cm}^{-1}$, the $\mathrm{C}-\mathrm{O}$ stretching at 1,130 and $1,088 \mathrm{~cm}^{-1}$ and the $-\mathrm{OH}$ bending at $1,043 \mathrm{~cm}^{-1}$. It was also identified the peak at $872 \mathrm{~cm}^{-1}$, which corresponds to the $-\mathrm{C}$-C- stretching of the amorphous phase (Muller et al., 2017).

No relevant variations in the chemical structure of the PLA were observed with the presence of the nanoparticles (LNP or $\mathrm{CNC}$ ) or the $\mathrm{AI}$ in both monolayers (Figure 2B) and bilayers films (Figure 2C), even if few variations are found: in the case of monolayer films, peak at $872 \mathrm{~cm}^{-1}$ was not found in presence of nanofillers and AI, indicating a variation in the crystallization behavior of the films (Scaffaro and Lopresti, 2018), while the signal at 1,454 and $1,265 \mathrm{~cm}^{-1}$, respectively due to the $\mathrm{CH}_{3}$ bending and C-O stretching were less evident. A double peak was also observed at $1,044 \mathrm{~cm}^{-1}$, typically related to $-\mathrm{OH}$ bending (Scaffaro et al., 2016).

Only the characteristic peaks of the lignin nanoparticles were more visible in the PLA_3LNP/PLA_15UMB bilayer film, in details the peaks at $1,163,1,055$, and $1,025 \mathrm{~cm}^{-1}$, which correspond to the $\mathrm{C}-\mathrm{O}-\mathrm{C}$ symmetric and antisymmetric stretching, $\mathrm{C}-\mathrm{O}$ stretching modes, $\mathrm{C}-\mathrm{H}$ bond in guaiacyl ring have been detected (Wang et al., 2016; Hidayati et al., 2018).

\section{Morphological Characterization}

The fractured surfaces of the PLA based films studied by FESEM are shown in Figure 3. PLA film showed a smooth and homogeneous surface, which was in general preserved in the monolayer films containing the nanoparticles as well as the AI, highlighting a good interface interaction between LNP or CNC and PLA matrix. The surfaces appeared homogeneous, this phenomenon was due to a good dispersion of nanofillers induced by the adopted process. Furthermore, the monolayer film combined with CNC (PLA_3CNC) was characterized by a rougher fractured surface with respect of neat PLA and PLA_3LNP, underlining a more brittle tendency of this formulation (Yang et al., 2016b). The addition of UMB at $15 \%$ wt. affected the homogeneity and uniformity of PLA fractured surface, showing a ductile surface morphology for AI containing system. Nevertheless, better adhesion was observed in the bilayer films in presence of UMB: in PLA/PLA_15UMB, PLA_3CNC/PLA_15UMB, and PLA_3LNP/PLA_15UMB, thermo-compression leads to a good homogeneity of the films and complete adhesion of the two polymeric layers (Requena et al., 2016). In addition, the thickness of bilayer sheets was limited during thermo-compression to a different extent, depending on the film (Table 1). In fact, the overall measured thickness for bilayers was lower than the theoretical value (sum of each layer thickness). In case of film containing the AI, UMB incorporation promoted the flow of PLA layers, which suggests the UMB diffusion into the matrix, producing a plasticizing effect and greater thickness reduction (Muller et al., 2017).

\section{Light Transmission and Color Properties}

Optical properties are essential when a material is considered to be used for food packaging purposes and consumer acceptability is directly related to their color attributes. Color parameters of the different formulations are reported in Table 1. Pristine PLA showed a high $\mathrm{L}^{*}$ value representative of its brightness and transparency, while its colorless nature is consistent with $\mathrm{a}^{*}$ and $\mathrm{b}^{*}$ values close to zero. Similar results were obtained for PLA_3CNC film. However, luminosity $\left(\mathrm{L}^{*}\right)$ value of the PLA_3LNP and PLA_15UMB was lower than that of the PLA film and the increment of the parameters $a^{*}$ and $\mathrm{b}^{*}$ are indicative of a red-yellowish coloration, which is due to the typical color of LNP and AI. This tendency 

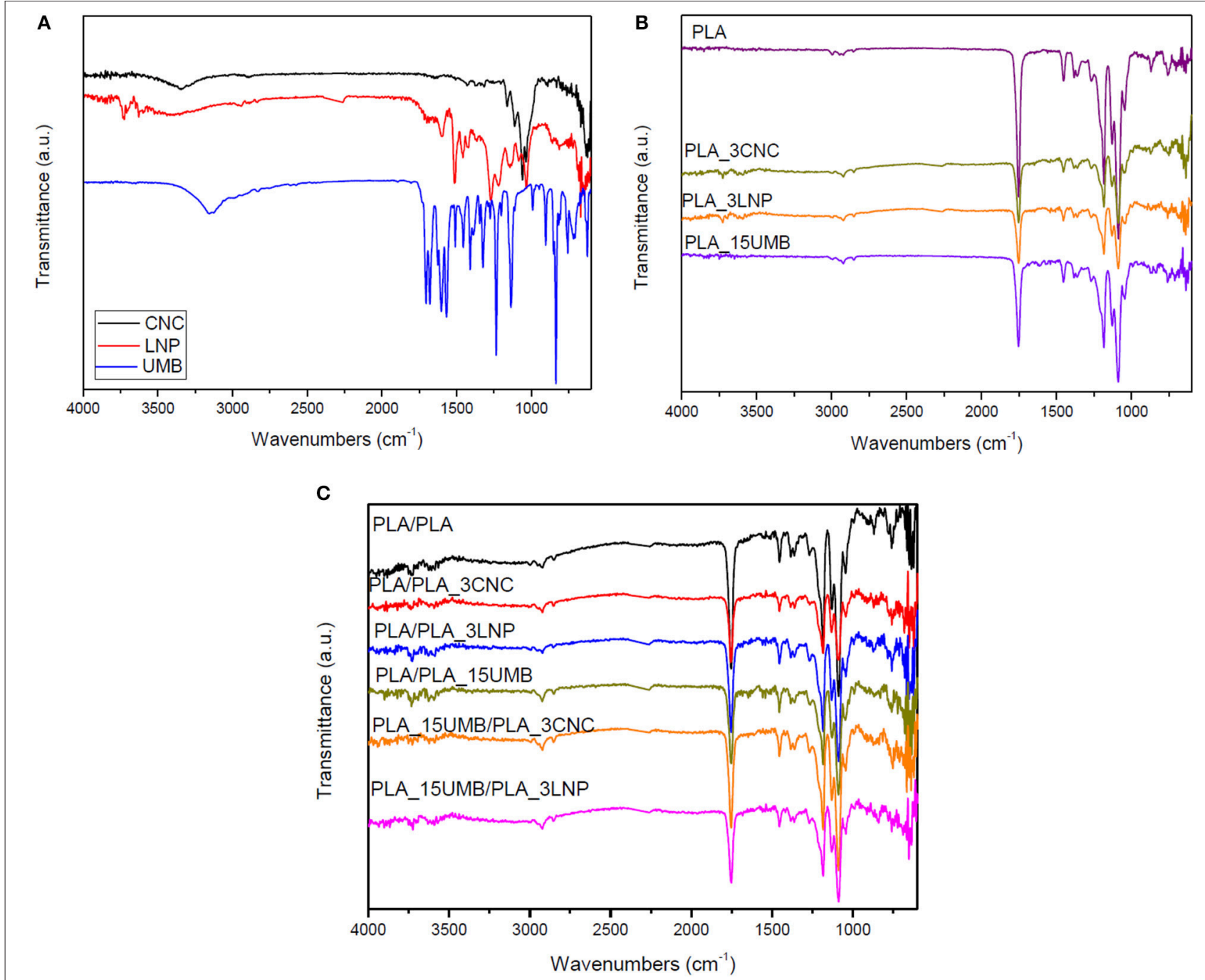

FIGURE 2 | FTIR spectra of nanofillers (CNC and LNP) and Al (A), PLA and PLA nanocomposites monolayer films (B), and bilayer films (C).
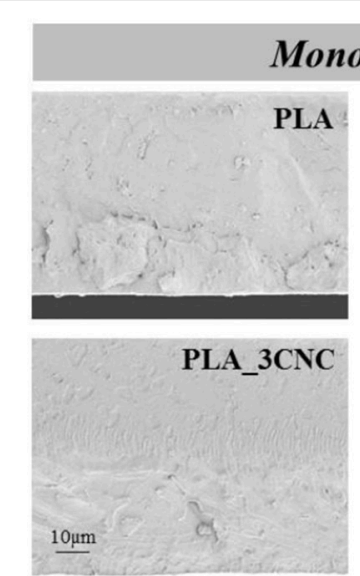

\section{Monolayer}

LA

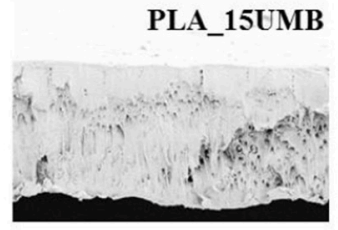

F

PLA 3LNP

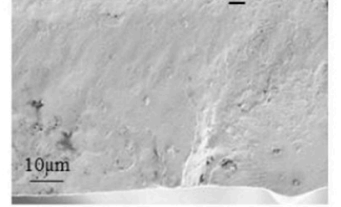

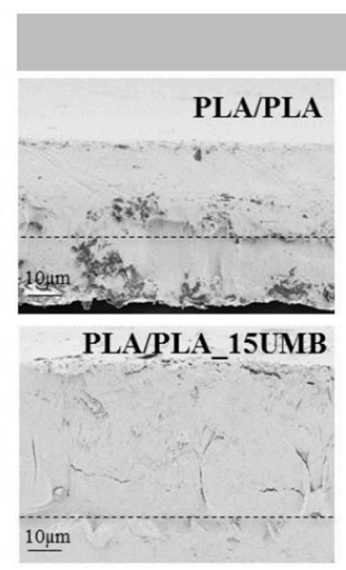

Bilayer
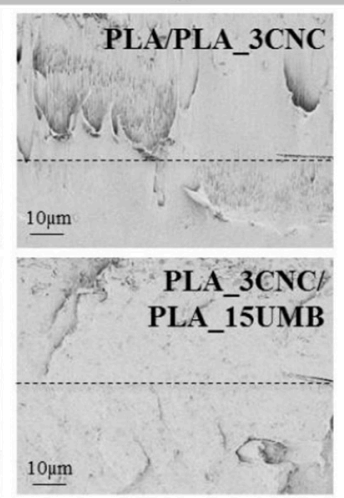

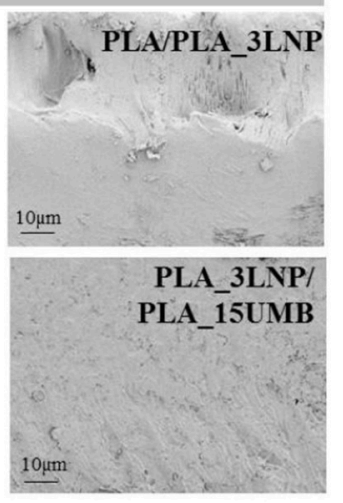

FIGURE 3 | FESEM micrographs of cross-sections of PLA nanocomposites monolayer and bilayer films. 
TABLE 1 | Thickness (mean value, $\mu \mathrm{m}$ ) and color parameters for PLA (neat and nanocomposites) monolayer and bilayer films.

\begin{tabular}{|c|c|c|c|c|c|c|}
\hline Formulations & Thickness $(\mu \mathrm{m})$ & $\mathbf{L}^{*}$ & $a^{*}$ & $\mathbf{b}^{*}$ & $\Delta \mathrm{E}^{\star}$ & Gloss $\left({ }^{\circ}\right)$ \\
\hline White control & & $99.47 \pm 0.00$ & $-0.08 \pm 0.01$ & $-0.08 \pm 0.01$ & - & $121 \pm 0$ \\
\hline \multicolumn{7}{|l|}{ MONOLAYER } \\
\hline PLA & $53.9 \pm 8.2$ & $97.39 \pm 0.04$ & $-0.06 \pm 0.00$ & $0.20 \pm 0.02$ & $0.63 \pm 0.04$ & $254 \pm 8$ \\
\hline PLA_3CNC & $118.8 \pm 25.9$ & $98.06 \pm 0.10$ & $-0.13 \pm 0.02$ & $0.70 \pm 0.03$ & $1.62 \pm 0.07$ & $129 \pm 2$ \\
\hline PLA_3LNP & $140.0 \pm 15.5$ & $73.58 \pm 2.920$ & $5.41 \pm 0.34$ & $30.31 \pm 1.77$ & $40.32 \pm 3.20$ & $93 \pm 3$ \\
\hline PLA_15UMB & $62.0 \pm 8.4$ & $85.34 \pm 0.50$ & $3.53 \pm 0.15$ & $18.79 \pm 0.43$ & $23.85 \pm 0.66$ & $37 \pm 2$ \\
\hline \multicolumn{7}{|l|}{ BILAYER } \\
\hline PLA/PLA & $81.5 \pm 10.3$ & $98.78 \pm 0.05$ & $-0.09 \pm 0.00$ & $0.26 \pm 0.02$ & $0.77 \pm 0.05$ & $163 \pm 9$ \\
\hline PLA/PLA_3CNC & $127.1 \pm 20.0$ & $97.13 \pm 0.40$ & $-0.14 \pm 0.03$ & $1.88 \pm 0.23$ & $3.05 \pm 0.44$ & $135 \pm 7$ \\
\hline PLA/PLA_3LNP & $119.3 \pm 8.4$ & $78.66 \pm 1.39$ & $4.09 \pm 0.17$ & $26.17 \pm 1.25$ & $33.76 \pm 1.84$ & $98 \pm 4$ \\
\hline PLA/PLA_15UMB & $89.4 \pm 11.5$ & $85.46 \pm 0.28$ & $3.82 \pm 0.11$ & $18.59 \pm 0.31$ & $23.66 \pm 0.42$ & $45 \pm 0$ \\
\hline PLA_3CNC/PLA_15UMB & $123.5 \pm 17.3$ & $88.86 \pm 0.97$ & $2.02 \pm 0.19$ & $13.56 \pm 0.18$ & $17.42 \pm 0.74$ & $71 \pm 1$ \\
\hline PLA_3LNP/PLA_15UMB & $102.0 \pm 18.7$ & $52.95 \pm 2.30$ & $12.37 \pm 0.50$ & $32.29 \pm 0.52$ & $58.04 \pm 1.84$ & $40 \pm 3$ \\
\hline
\end{tabular}

was also reflected in the significant value of the total color difference $(\Delta \mathrm{E})$ relative to the control. Bilayer films followed a similar tendency than the monolayer materials according the type of nanoparticle or AI added to the PLA. Then, PLA_3LNP/PLA_15UMB was the least transparent and the most yellowish film among the materials studied (Masek, 2015; Pagno et al., 2016). Mono and bilayer films showed also a lower gloss value than the pristine PLA film: the lowest value among the monolayer films was measured for the PLA_15UMB sample, due to the poorer dispersion of the AI in the PLA matrix. The results of the bilayer films are consistent with the corresponding monolayer ones and they are probably also influenced by the processing method used to mold the bilayers (Iiguez-Franco et al., 2012).

$\mathrm{UV}$-Vis characterization of the produced materials was also performed and related results for monolayer and bilayer films are reported in Figure 4. PLA film showed a high transparency, since it exhibited a high transmittance percentage in the entire measured wavelength region. The addition of LNP reduced the transmittance in the visible region, reaching rather null values at wavelength lower than $350 \mathrm{~nm}$ in the UV region, demonstrating the potential applicability of PLA_LNP as all-biomass packaging and coating systems characterized by exceptional transparency and UV-protection capability, mainly significant for lightsensitive products (Kim et al., 2017). A food packaging material is expected to be transparent to visible light and opaque in the UV region, in order to protect the food from the oxidative deterioration, discoloration and flavors losses causes by the UV radiation (Li et al., 2014).

The transparency of PLA_15UMB film is radically reduced above $350 \mathrm{~nm}$, being this behavior induced by the presence of UMB that absorbs the light between 320 and $412 \mathrm{~nm}$ (Abu-Eittah and El-Tawil, 1985; Luzi et al., 2018b). Inversely, the addition of CNC did not modify the transparency of the PLA films. In a previous work it was found that $\mathrm{PHB} / \mathrm{CNC}$ films are more transparent than films of pristine polymer (Seoane et al., 2017).

In bilayer films, PLA/PLA and PLA/PLA_3CNC showed a high light transmission as the respective monolayers did. On the other hand, the presence of an additional PLA layer in PLA/PLA_3LNP induced a further decrease of the signal in the visible region and UV protection substantially unchanged with respect of monolayer. The others bilayer formulations also behave rather transparent in the visible region and opaque in the UV section, which is an advantage for the possible application of the materials. The behavior was basically the same, with a general similar trend but a reduced intensity of the signal in of PLA/PLA_15UMB and PLA_3LNP/PLA_15_UMB, where LNP and $\mathrm{AI}$ acted in a synergic manner to modulate the transparency. Surprisingly, the combination of $\mathrm{CNC}$ and $\mathrm{UMB}$ in the bilayer system (PLA_3CNC/PLA_15UMB) induces significant improvements in terms of visible transparency, in accordance with results for color estimation (Table 1). Similar results were obtained by Aulin et al. (2013), where the polymer/NFC assembly with some minor nanofibrils aggregation resulting in surface light scattering and a slightly lower light transmittance and in a similar approach, by Halász et al. (2015), that proved retained transparency for PLA films coated with 4 layers of CNC in a layer-by-layer self-assembly methodology.

\section{Thermal Properties}

DSC tests of PLA-based mono and bilayer films were also carried out in order to investigate the role of AI and biobased nanofillers on polymer thermal characteristics. Figures 5A,B and Table 2 summarize the acquired data. No significant variations in $\mathrm{T}_{\mathrm{g}}$ and $\mathrm{T}_{\mathrm{m}}$ neither in the percentage of cristallinity were found with the addition of CNC or LNP to PLA matrix.

Incorporation of amorphous lignin nanoparticles led to less crystalline regions established in the monolayer systems: in comparison with other biopolymer nanoparticles that they could facilitate the crystallization phenomenon through the nucleation phase, lignin nanoparticles are characterized by reduced contribution to the PLA crystal formation and growth, even though they were compatible with PLA (Kubo and Kadla, 2003). As evidenced by XRD analysis, the crystalline structure of the PLA_3LNP and PLA_3CNC system was nearly the same as that of neat PLA film. 

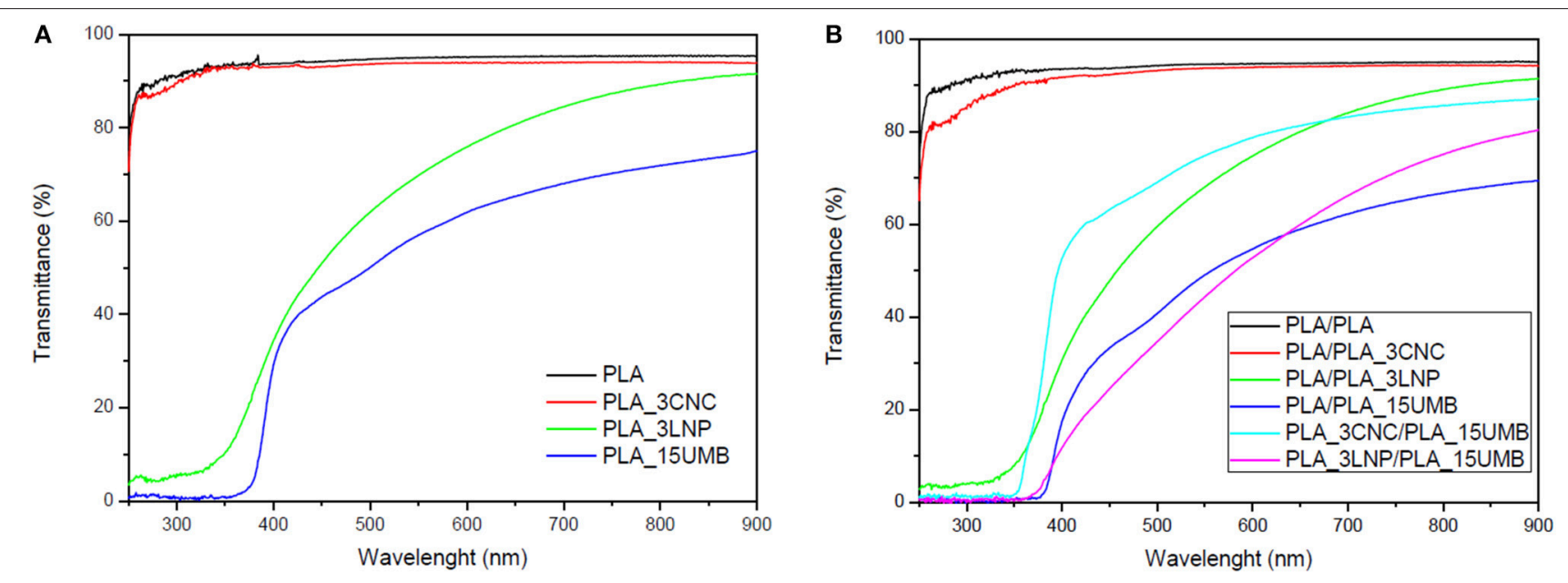

FIGURE 4 | UV-vis spectra of PLA and PLA nanocomposites (A) monolayer films; (B) bilayer films.

However, a reduction in $\mathrm{T}_{\mathrm{g}}$ and $\mathrm{T}_{\mathrm{cc}}$, as well as an increment in the percentage of crystallinity, was observed in the PLA_15UMB film compared to neat PLA, probably due to a plasticizing effect of UMB on the PLA matrix (López-de-Dicastillo et al., 2012), in accordance to XRD and FTIR results.

In the case of bilayer films, a similar reduction in $T_{g}$ was observed for the systems containing the AI.

Moreover, the thermogram of PLA/PLA_15UMB showed a delineated endothermic peak, respect to other systems, this phenomenon can be ascribed to the glass transition, which it is normally related to a stronger stress relaxation on heating, particularly in the presence of an ingredient with a plasticizing effect in the polymeric thin systems, in accordance to the results of Fortunati and co-authors in presence of limonene containing PLA films (Fortunati et al., 2014).

An evidence of the CNC pivot role in promoting the crystallization in multilayer films can be found in the reduced $\mathrm{T}_{\mathrm{cc}}$ values, even in presence of a microscale AI $\left(108\right.$ and $103^{\circ} \mathrm{C}$, respectively for PLA/PLA_3CNC and PLA_3CNC/PLA_15UMB films): in addition, the combination of both UMB and CNC in the bilayer induced a further crystallization event (that can be identified in the shoulder peak at $\mathrm{T}=120^{\circ} \mathrm{C}$, coincident with the cold crystallization temperature of PLA/PLA_15UMB).

In order to investigate the presence of the additives and their behavior upon processing, thermal degradation analysis of the mono and bilayer films was performed. The derivative curves of residual mass vs. temperature are shown in Figures 5C,D for the mono and bilayer films, respectively.

PLA showed a single degradation process under nitrogen atmosphere, with a maximum degradation temperature $\left(\mathrm{T}_{\mathrm{d}}\right)$ at $305^{\circ} \mathrm{C}$. It was observed that $\mathrm{T}_{\mathrm{d}}$ values of the PLA-nanocomposites are higher than that of the PLA, due to the barrier effect of the nanoparticles. Lignin nanocomposites showed the highest increment of $T_{d}$, which is consistent with its charring forming characteristics of polyphenolic LNP (Gupta et al., 2014), while CNC confirmed their ability to increase the thermal stability of
PLA and slowing down the rate of thermal degradation (Fortunati et al., 2012; Khoo et al., 2016).

PLA_15UMB showed a reduced degradation rate, but an anticipated $\mathrm{T}_{\text {onset }}$, in comparison with PLA_3LNP and this behavior can be correlated to the thermo stability of the respective filler, as already evidenced by $\mathrm{He}$ et al. (2018) and Luzi et al. (2018b). PLA/PLA and PLA/PLA_3CNC bilayer films exhibited increased thermal stability compared to the corresponding monolayer films. This behavior could be related to the increment in the percentage of cristallinity of the samples, as it was observed by DSC (Table 2). While, the $T_{d}$ of PLA_15UMB was higher than that of PLA/PLA_15UMB, probably due to a plasticizing effect of UMB and a diminution in the Xc in the bilayer system. The combined effect of $\mathrm{CNC}$ and UMB lead to a $\mathrm{Td}$ of $340^{\circ} \mathrm{C}$ which could be related to the UMB diffusion during thermocompression, as explained previously by XRD, as well as to the increment of $\mathrm{X}_{\mathrm{c}}$. Both mono and bilayers films completely degrade at the end of the test at $800^{\circ} \mathrm{C}$.

\section{Mechanical Properties}

Figure 6 shows the typical stress-strain curves of PLA based systems and the results of tensile test in terms of modulus, strength and elongation at break are listed in Table 3. Regarding tensile properties, the presence of $3 \%$ of nanoparticles provokes a decrease in the elongation at break of the PLA films respect to the neat polymer, which is a common trend observed for thermal processable nanocomposites (Yang et al., 2015a; Ferreira et al., 2018). However, no relevant increment in the modulus and tensile strength was observed with the addition of the nanoparticles. This behavior could be due to the poor dispersion of the nanoparticles reducing their interactions with the PLA matrix. A remarkable improvement in the elongation as break was achieved with the AI addition in the PLA film, which was not kept in the bilayer materials. The presence of both the nanoparticle and the $\mathrm{AI}$ in each film enhance the modulus and the tensile strength of the bilayer material, assuming a good interface adhesion controlling the bilayer resistance. If a probable 

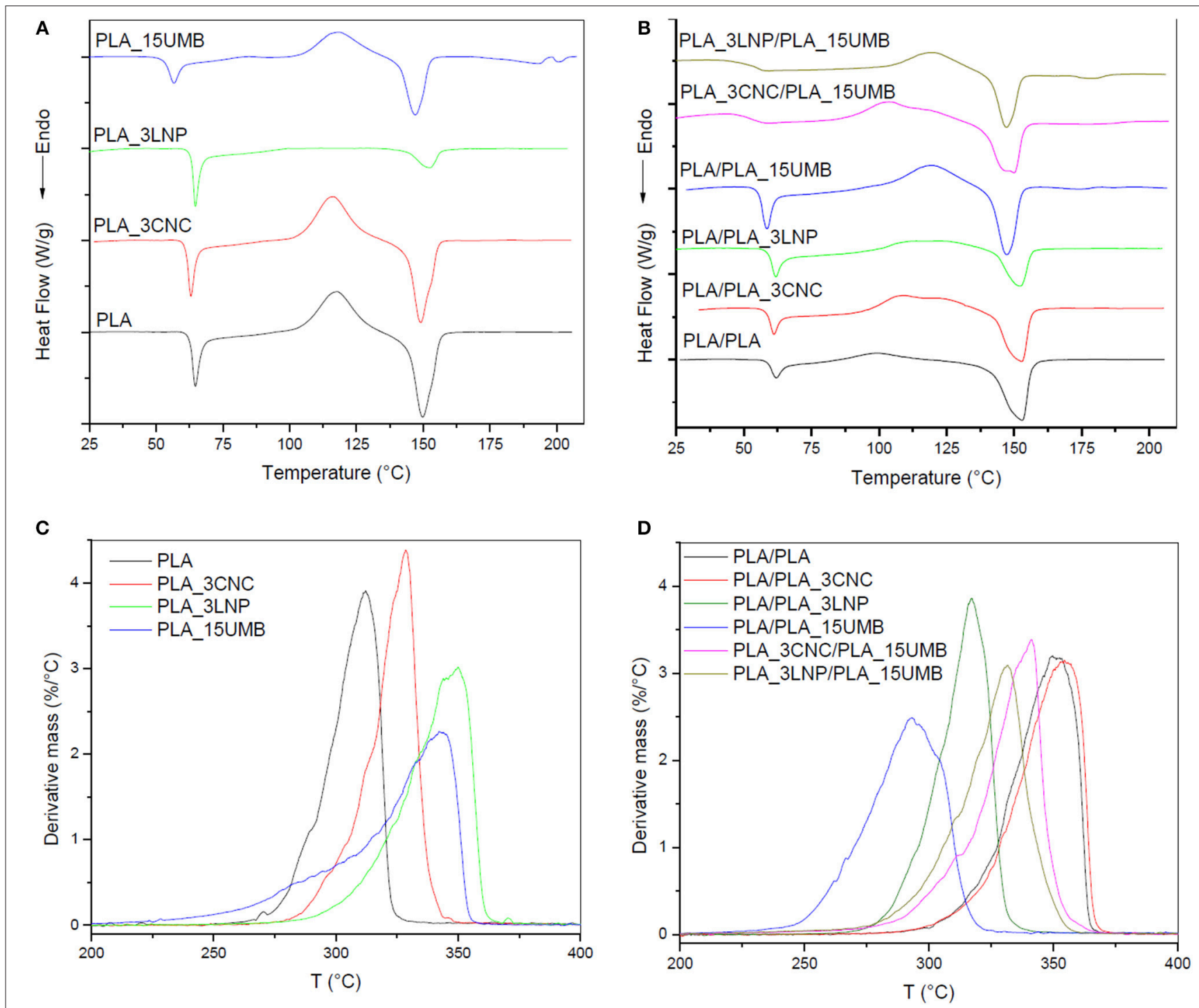

FIGURE 5 | DSC (first heating scans) and derivative mass loss curves of PLA and PLA nanocomposites monolayer (A-C) and bilayer (B-D) films.

TABLE 2 | Thermal properties from DSC first heating scans of PLA (neat and nanocomposites) monolayer and bilayer films.

\begin{tabular}{|c|c|c|c|c|c|c|}
\hline Formulation & $\operatorname{Tg}\left({ }^{\circ} \mathrm{C}\right)$ & $\operatorname{Tcc}\left({ }^{\circ} \mathrm{C}\right)$ & $\Delta \mathrm{Hcc}(\mathrm{J} / \mathrm{g})$ & $\operatorname{Tm}\left({ }^{\circ} \mathrm{C}\right)$ & $\Delta \mathrm{Hm}(\mathrm{J} / \mathrm{g})$ & Xc (\%) \\
\hline \multicolumn{7}{|l|}{ MONOLAYER } \\
\hline PLA & 63 & 118 & 24 & 150 & 28 & 5 \\
\hline PLA_3CNC & 62 & 116 & 28 & 149 & 30 & 2 \\
\hline PLA_3LNP & 63 & 126 & 4 & 152 & 7 & 3 \\
\hline PLA_15UMB & 55 & 84 & 1 & 147 & 26 & 12 \\
\hline \multicolumn{7}{|l|}{ BILAYER } \\
\hline PLA/PLA_3LNP & 60 & 112 & 8 & 152 & 16 & 9 \\
\hline PLA/PLA_15UMB & 57 & 119 & 20 & 147 & 24 & 6 \\
\hline PLA_3CNC/ PLA_15UMB & 53 & 103 & 17 & 150 & 28 & 14 \\
\hline PLA_3LNP/ PLA_15UMB & 55 & 120 & 13 & 147 & 17 & 7 \\
\hline
\end{tabular}




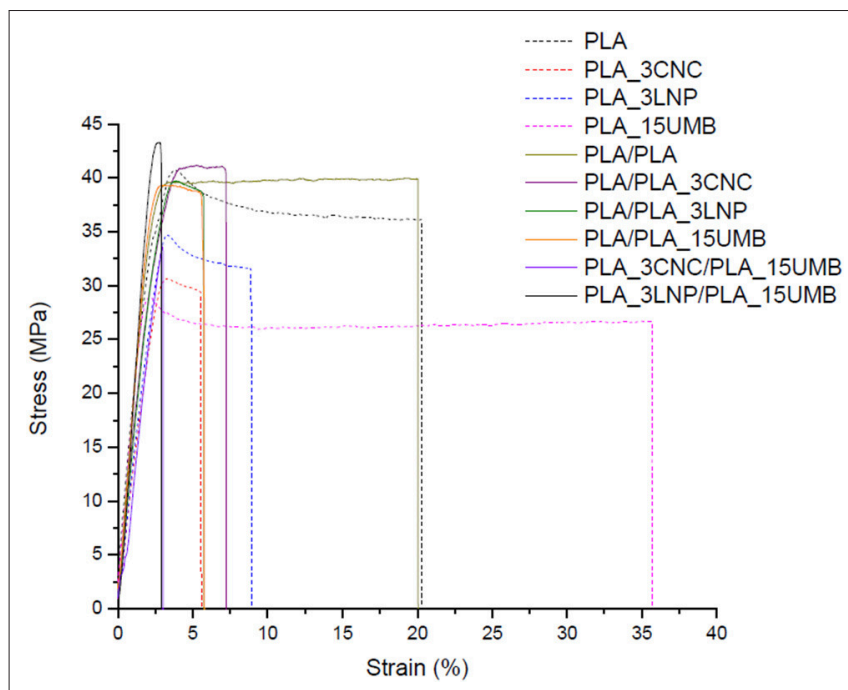

FIGURE 6 | Stress-strain curves of PLA (neat and nanocomposites) monolayer and bilayer films.

TABLE 3 | Tensile properties [elastic modulus (E), tensile strength (TS) and elongation at break $(\boldsymbol{\varepsilon})$ ] of PLA (neat and nanocomposites) monolayer and bilayer films.

\begin{tabular}{lccc}
\hline $\begin{array}{l}\text { Formulation } \\
\text { MONOLAYER }\end{array}$ & E (GPa) & TS (MPa) & $\boldsymbol{\varepsilon}(\%)$ \\
PLA & & & \\
PLA_3CNC & $1.4 \pm 0.2$ & $41.5 \pm 3.9$ & $16.2 \pm 4.2$ \\
PLA_3LNP & $1.2 \pm 0.1$ & $28.1 \pm 4.0$ & $4.9 \pm 0.8$ \\
PLA_15UMB & $1.3 \pm 0.1$ & $34.2 \pm 1.5$ & $8.4 \pm 0.9$ \\
BILAYER & $1.2 \pm 0.3$ & $28.8 \pm 9.3$ & $37.0 \pm 4.2$ \\
PLA/PLA & & & \\
PLA/PLA_3CNC & $1.6 \pm 0.2$ & $35.0 \pm 6.2$ & $16.4 \pm 5.3$ \\
PLA/PLA_3LNP & $1.4 \pm 0.1$ & $38.3 \pm 2.9$ & $5.6 \pm 1.2$ \\
PLA/PLA_15UMB & $1.5 \pm 0.3$ & $36.7 \pm 4.1$ & $6.3 \pm 0.8$ \\
PLA_3CNC/ PLA_15UMB & $1.6 \pm 0.1$ & $38.4 \pm 2.2$ & $4.5 \pm 0.9$ \\
PLA_3LNP/ PLA_15UMB & $2.0 \pm 0.1 \pm 0.1$ & $52.9 \pm 2.2$ & $2.9 \pm 0.3$ \\
\end{tabular}

use of these materials is as packaging, high elongation at break and enhanced mechanical resistance are necessary.

\section{Antioxidant Activity}

Antioxidant capacity of the mono and bilayer films was measured and expressed as radical scavenging activity (RSA). The values are listed in Table 4. Figure 7 shows the color variation of the DPPH methanol solution for PLA mono and bilayer neat and nanocomposites films.

LNP produced the highest antioxidant activity in the monolayer formulations reaching a RSA value of $80 \%$, as previously reported in Yang et al. (2018), while CNC did not show a significant radical scavenging activity in the PLA matrix. On the other hand, UMB was able to limit the oxidation by donating hydrogen from the phenolic hydroxyl groups, by formation of a stable end product, unable to initiate or propagate oxidation of the lipids (Murthy and Naidu, 2012). The same trend was
TABLE 4 | Radical scavenging activity (RSA) values for PLA (neat and nanocomposites) monolayer and bilayer films.

\begin{tabular}{lc}
\hline Formulations & DPPH scavenging activity, RSA (\%) \\
\hline MONOLAYER & - \\
PLA & 2.5 \\
PLA_3CNC & 80.4 \\
PLA_3LNP & 45.2 \\
PLA_15UMB & \\
BILAYER & - \\
PLA/PLA & 6.8 \\
PLA/PLA_3CNC & 62.0 \\
PLA/PLA_3LNP & 54.0 \\
PLA/PLA_15UMB & 32.3 \\
PLA_3CNC/PLA_15UMB & 70.7 \\
PLA_3LNP/PLA_15UMB & \\
\hline
\end{tabular}

Time $=1 \mathrm{~h}$

maintained even in the case of bilayer films in presence of CNC, while LNP in the layered PLA showed reduced activity, due to a limited diffusion of these additives in thicker films. On the other hand, the incorporation of UMB in the bilayer PLA films induced the highest RSA among those materials, due to the synergistic effect of both additives. The presence of UMB causes a clear effect of RSA \%: the highest effect is related by the incorporation of LNP respect to CNC (RSA (\%): PLA_3CNC/PLA_15UMB $=32.3 \%$ and PLA_3LNP/PLA_15UMB $=70.7 \%$ ), definitively higher than the corresponding PLA/PLA_3CNC=6.8\% and PLA/PLA_3LNP $=60.2 \%$ (López et al., 2007; Luzi et al., 2018b).

This phenomenon has been reported for polymeric films containing epicatechin, quercetin, catechin, caffeine, gallic acid, in which the antioxidant effect was proportional to the antioxidant content in the simulant. Similar behavior was observed by using extracts obtained from different varieties of grapes, the antioxidant activity increases with the concentration of the phenolic compounds (López-de-Dicastillo et al., 2010).

\section{CONCLUSIONS}

Bilayer films based on PLA were obtained by extrusion followed by monolayer thermo-compression. CNC and LNP as well as an active ingredient (UMB) were added to the formulation in order to improve the PLA properties as food packaging material.

No significant variations in the chemical structure of PLA with the presence of the nanoparticles or UMB in both monolayers and bilayers films were observed by FTIR. Fractured surfaces of the PLA based films studied by FESEM revealed a homogeneous morphology with the nanoparticles addition while a less uniform surface was observed for UMB containing system. Additionally, a reduction in the bilayer thickness was observed compared to sum of each monolayer.

Brightness and transparency of PLA was not affected by the CNC addition, while LNP and UMB notably reduce the luminosity of both the mono and bilayer materials. However, the PLA_3CNC/PLA_15UMB bilayer system showed a notable 


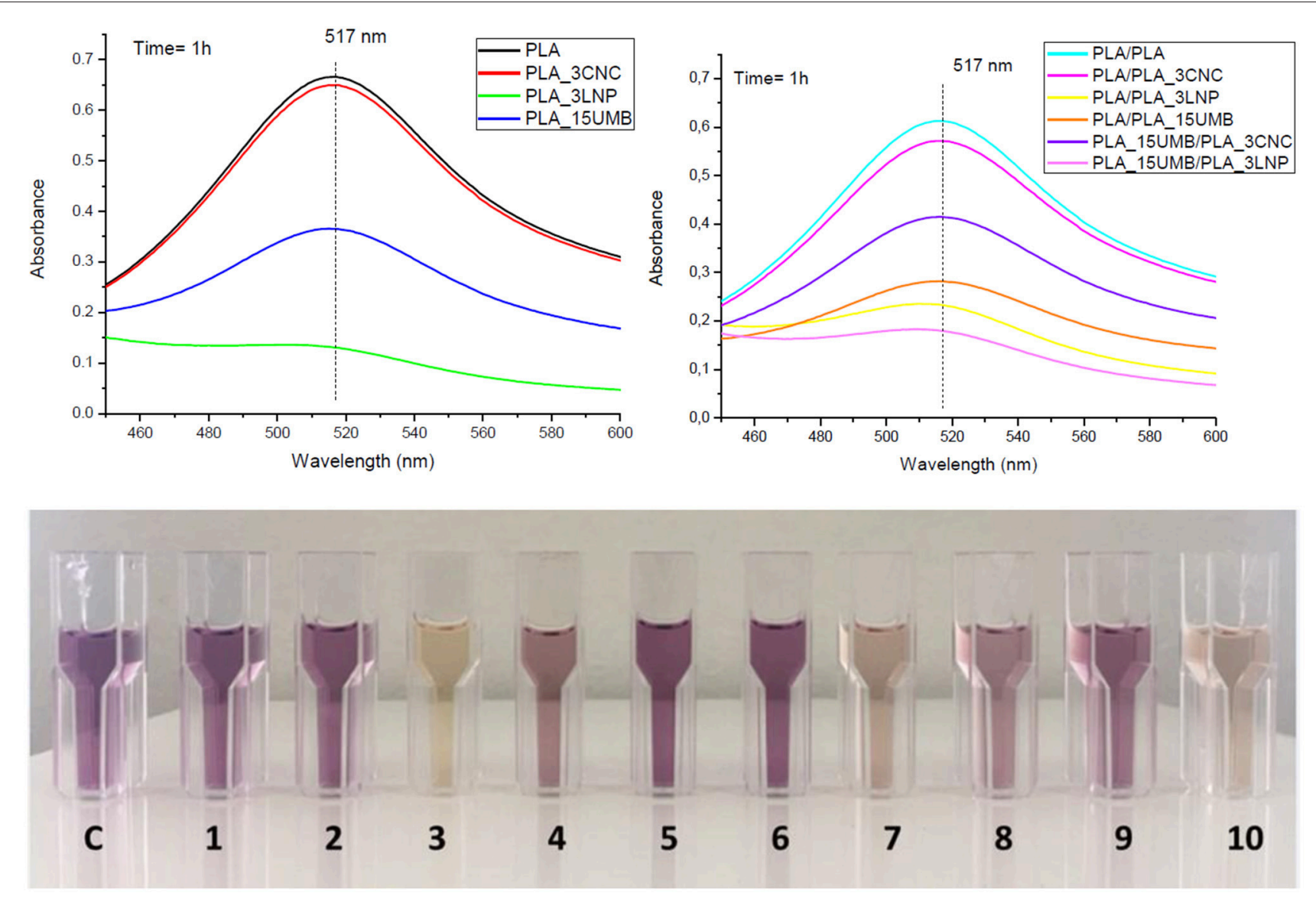

FIGURE 7 | Antioxidant activities of PLA (neat and nanocomposites) monolayer and bilayer films evaluated by UV absorbance of DPPH at $517 \mathrm{~nm}$ monitored after $1 \mathrm{~h}$ and color variation of the DPPH methanol solution (C = control, $1=$ PLA, $2=$ PLA_3CNC, $3=$ PLA_3LNP, $4=$ PLA_15UMB, $5=$ PLA/PLA, $6=$ PLA/PLA_3CNC, 7 = PLA/PLA_3LNP, 8 = PLA/PLA_15UMB, 9 = PLA_15UMB/PLA_3CNC, 10 = PLA_15UMB/PLA_3LNP).

transparency in the visible region. All the materials showed a good protection against UV light what is an advantage considering their use as food packaging.

A plasticizing effect of UMB on the PLA matrix was noticed in accordance with the $\mathrm{T}_{\mathrm{g}}$ and $\mathrm{T}_{\mathrm{cc}}$ reduction observed by DSC. This was in agreement to XRD and FTIR results. The percentage of PLA cristallinity was generally enhanced in the bilayer films respect to the monolayer ones which was also evidenced in the thermal resistance increment of those bilayer films. $\mathrm{T}_{\mathrm{d}}$ of monolayer PLA-nanocomposites were higher than that of PLA due to the barrier effect of the nanoparticles, however UMB reduced the $T_{d}$ due to its own lower thermo stability.

Regarding mechanical properties, monolayers showed an increment in the elongation at break compared to the bilayer systems, with a reduction in the modulus and tensile strength according to the relative cristallinity values of the samples. Moreover, a notable enhancement in the elongation at break was reached with the UMB addition to the PLA film due to the plasticizing effect of the AI.

LNP produced the highest antioxidant activity in the monolayer formulations while the combined incorporation of
LNP and UMB in the bilayer PLA films induced the highest antioxidant activity due to the synergistic effect of both additives.

\section{DATA AVAILABILITY}

All datasets generated for this study are included in the manuscript and/or the supplementary files.

\section{AUTHOR CONTRIBUTIONS}

MI, DP, FL, and FD contributed to conception and design of the study. MI, LM, and VC wrote the first draft of the manuscript. MI, DP, and FL wrote sections of the manuscript. All authors contributed to manuscript revision, read and approved the submitted version.

\section{ACKNOWLEDGMENTS}

The authors gratefully acknowledge the support from the National Research Council of Argentina, CONICET (PIP 0527) and ANCyPT (PICT 2034) and the National University of Mar del Plata. 


\section{REFERENCES}

Abdelwahab, M. A., Flynn, A., Chiou, B.-S., Imam, S., Orts, W., and Chiellini, E. (2012). Thermal, mechanical and morphological characterization of plasticized PLA-PHB blends. Polym. Degrad. Stab. 97, 1822-1828. doi: 10.1016/j.polymdegradstab.2012.05.036

Abu-Eittah, R. H., and El-Tawil, B. A. H. (1985). The electronic absorption spectra of some coumarins. A molecular orbital treatment. Can. J. Chem. 63, 1173-1179. doi: 10.1139/v85-200

Arrieta, M. P., López, J., Ferrándiz, S., and Peltzer, M. A. (2013). Characterization of PLA-limonene blends for food packaging applications. Polym. Test. 32, 760-768. doi: 10.1016/j.polymertesting.2013.03.016

Arrieta, M. P., López, J., López, D., Kenny, J. M., and Peponi, L. (2016). Effect of chitosan and catechin addition on the structural, thermal, mechanical and disintegration properties of plasticized electrospun PLA-PHB biocomposites. Polym. Degr. Stabil. 132 (Suppl. C), 145-156. doi: 10.1016/j.polymdegradstab.2016.02.027

ASTM D523 (2018). Standard Test Method for Specular Gloss.

Aulin, C., Karabulut, E., Tran, A., Wgberg, L., and Lindstr, T. (2013). Transparent nanocellulosic multilayer thin films on polylactic acid with tunable gas barrier properties. ACS Appl. Mater. Interfaces 5, 7352-7359. doi: 10.1021/am401700n

Banerjee, R., Verma, A. K., and Siddiqui, M. W. (2017). "Control of lipid oxidation in muscle food by active packaging technology," in Natural Antioxidants, eds R. Banerjee, A. K. Verma, and M. W. Siddiqui (New York, NY: Apple Academic Press), 363-402.

Bassett, K. H., Liang, C. Y., and Marchessault, R. H. (1963). The infrared spectrum of crystalline polysaccharides. IX. The near infrared spectrum of cellulose. J. Polym. Sci. A General Papers 1, 1687-1692. doi: 10.1002/pol.1963.100010520

Byun, Y., , Kim, Y. T., and Whiteside, S. (2010). Characterization of an antioxidant polylactic acid (PLA) film prepared with a -tocopherol, BHT and polyethylene glycolusing film cast extruder. J. Food Eng. 100, 239-244. doi: 10.1016/j.jfoodeng.2010.04.005

Castro López, M. M., López de Dicastillo, C., López Vilariño, J. M., and González Rodríguez, M. V. (2013). Improving the capacity of polypropylene to be used in antioxidant active films: incorporation of plasticizer and natural antioxidants. J. Agric. Food Chem. 61, 8462-8470. doi: 10.1021/jf402670a

Cerruti, P., Malinconico, M., Rychly, J., Matisova-Rychla, L., and Carfagna, C. (2009). Effect of natural antioxidants on the stability of polypropylene films. Polym. Degrad. Stab. 94, 2095-2100. doi: 10.1016/j.polymdegradstab.2009.07.023

Chaiwutthinan, P., Pimpan, V., Chuayjuljit, S., and Leejarkpai, T. (2015). Biodegradable plastics prepared from poly (lactic acid), poly (butylene succinate) and microcrystalline cellulose extracted from wastecotton fabric with a chain extender. J. Polym. Environ. 23, 114-125. doi: 10.1007/s10924-014-0689-0

Chung, Y.-L., Olsson, J. V., Li, R. J., Frank, C. W., Waymouth, R. M., Billington, S. L., et al. (2013). A renewable lignin-lactide copolymer and application in biobased composites. ACS Sustain. Chem. Eng. 1, 1231-1238. doi: $10.1021 / \mathrm{sc} 4000835$

Domenek, S., Louaifi, A., Guinault, A., and Baumberger, S. (2013). Potential of lignins as antioxidant additive in active biodegradable packaging materials. $J$. Polym. Environ. 21, 692-701. doi: 10.1007/s10924-013-0570-6

Domínguez, R., Barba, F. J., Gómez, B., Putnik, P., Bursać Kovačevi,ć, D., Pateiro, M., et al. (2018). Active packaging films with natural antioxidants to be used in meat industry: a review. Food Res. Int. 113, 93-101. doi: 10.1016/j.foodres.2018.06.073

El-Wakil, N. A., Hassan, E. A., Abou-Zeid, R. E., and Dufresne, A. (2015). Development of wheat gluten/nanocellulose/titanium dioxide nanocomposites for active food packaging. Carbohydr. Polym. 124, 337-346. doi: 10.1016/j.carbpol.2015.01.076

Fabra, M. J., López-Rubio, A., and Lagaron, J. M. (2016). Use of the electrohydrodynamic process to develop active/bioactive bilayer films for food packaging applications. Food Hydrocoll. 55, 11-18. doi: 10.1016/j.foodhyd.2015.10.026

Fernandes, E. M., Pires, R. A., Mano, J. F., and Reis, R. L. (2013). Bionanocomposites from lignocellulosic resources: properties, applications and future trends for their use in the biomedical field. Prog. Polym. Sci. 38, 1415-1441. doi: 10.1016/j.progpolymsci.2013.05.013
Ferreira, F. V., Dufresne, A., Pinheiro, I. F., Souza, D. H. S., Gouveia, R. F., Mei, L. H. I., et al. (2018). How do cellulose nanocrystals affect the overall properties of biodegradable polymer nanocomposites: a comprehensive review. Eur. Polym. J. 108, 274-285. doi: 10.1016/j.eurpolymj.2018.08.045

Fortunati, E., Armentano, I., Zhou, Q., Iannoni, A., Saino, E., Visai, L., et al. (2012). Multifunctional bionanocomposite films of poly(lactic acid), cellulose nanocrystals and silver nanoparticles. Carbohydr. Polym. 87, 1596-1605. doi: 10.1016/j.carbpol.2011.09.066

Fortunati, E., Luzi, F., Fanali, C., Dugo, L., Belluomo, M. G., Torre, L., et al. (2016a). Hydroxytyrosol as active ingredient in poly (vinyl alcohol) films for food packaging applications. J. Renew. Materials 5, 81-95. doi: 10.7569/JRM.2016.634132

Fortunati, E., Luzi, F., Puglia, D., Dominici, F., Santulli, C., Kenny, J. M., et al. (2014). Investigation of thermo-mechanical, chemical and degradative properties of PLA-limonene films reinforced with cellulose nanocrystals extracted from Phormium tenax leaves. Eur. Polym. J. 56, 77-91. doi: 10.1016/j.eurpolymj.2014.03.030

Fortunati, E., Puglia, D., Luzi, F., Santulli, C., Kenny, J. M., and Torre, L. (2013). Binary PVA bio-nanocomposites containing cellulose nanocrystals extracted from different natural sources: part I. Carbohydr. Polym. 97, 825-836. doi: 10.1016/j.carbpol.2013.03.075

Fortunati, E., Yang, W., Luzi, F., Kenny, J., Torre, L., and Puglia, D. (2016b). Lignocellulosic nanostructures as reinforcement in extruded and solvent casted polymeric nanocomposites: an overview. Eur. Polym. J. 80, 295-316. doi: 10.1016/j.eurpolymj.2016.04.013

Ge, Y., Wei, Q., and Li, Z. (2014). Preparation and evaluation of the free radical scavenging activities of nanoscale lignin biomaterials. BioResources 9 , 6699-6706. doi: 10.15376/biores.9.4.6699-6706

Gorrasi, G., and Pantani, R. (2013). Effect of PLA grades and morphologies on hydrolytic degradation at composting temperature: assessment of structural modification and kinetic parameters. Polym. Degrad. Stab. 98, 1006-1014. doi: 10.1016/j.polymdegradstab.2013.02.005

Gupta, A. K., Mohanty, S., and Nayak, S. K. (2014). Synthesis, characterization and application of lignin nanoparticles (LNPs). Materials Focus 3, 444-454. doi: 10.1166/mat.2014.1217

Halász, K., Hosakun, Y., and Csóka, L. (2015). Reducing water vapor permeability of poly (lactic acid) film and bottle through layer-by-layer deposition of greenprocessed cellulose nanocrystals and chitosan. Int. J. Polym. Sci. 2015:954290. doi: 10.1155/2015/954290

He, X., Luzi, F., Yang, W., Xiao, Z., Torre, L., Xie, Y., et al. (2018). Citric acid as green modifier for tuned hydrophilicity of surface modified cellulose and lignin nanoparticles. ACS Sustain. Chem. Eng. 6, 9966-9978. doi: 10.1021/acssuschemeng.8b01202

Hidayati, S., Zuidar, A. S., Satyajaya, W., and Retnowati, D. (2018). Isolation and characterization of formacell Lignins from oil empty fruits bunches. IOP Conf. Ser. Mater. Sci. Eng. 344:012006. doi: 10.1088/1757-899X/344/1/012006

Iiguez-Franco, F., Soto-Valdez, H., Peralta, E., Ayala-Zavala, J. F., Auras, R., and Gámez-Meza, N. (2012). Antioxidant activity and diffusion of catechin and epicatechin from antioxidant active films made of poly (L-lactic acid). J. Agric. Food Chem. 60, 6515-6523. doi: 10.1021/jf300668u

Ittadwar, P. A., and Puranik, P. K. (2017). Novel umbelliferone phytosomes: development and optimization using experimental design approach and evaluation of photo-protective and antioxidant activity. Int. J. Pharm. Pharm. Sci. 9, 218-228. doi: 10.22159/ijpps.2017v9i1.14635

Jia, S., Yu, D., Zhu, Y., Wang, Z., Chen, L., and Fu, L. (2017). Morphology, crystallization and thermal behaviors of PLA-based composites: wonderful effects of hybrid GO/PEG via dynamic impregnating. Polymers 9:10. doi: 10.3390/polym9100528

Kalish, J. P., Aou, K., Yang, X., and Hsu, S. L. (2011). Spectroscopic and thermal analyses of $\alpha^{\prime}$ and $\alpha$ crystalline forms of poly(l-lactic acid). Polymer 52, 814-821. doi: 10.1016/j.polymer.2010.12.042

Kamal, M. R., and Khoshkava, V. (2015). Effect of cellulose nanocrystals (CNC) on rheological and mechanical properties and crystallization behavior of PLA/CNC nanocomposites. Carbohydr. Polym. 123, 105-114. doi: 10.1016/j.carbpol.2015.01.012

Khoo, R. Z., Ismail, H., and Chow, W. S. (2016). Thermal and morphological properties of poly (lactic acid)/nanocellulose nanocomposites. Procedia Chem. 19, 788-794. doi: 10.1016/j.proche.2016.03.086 
Kim, Y., Suhr, J., Seo, H.-W., Sun, H., Kim, S., Park, I.-K., et al. (2017). All biomass and UV protective composite composed of compatibilized lignin and poly (Lactic-acid). Sci. Rep. 7:43596. doi: 10.1038/srep43596

Kubo, S., and Kadla, J. F. (2003). The formation of strong intermolecular interactions in immiscible blends of poly (vinyl alcohol)(PVA) and lignin. Biomacromolecules 4, 561-567. doi: 10.1021/bm025727p

Lee, S. Y., Lee, S. J., Choi, D. S., and Hur, S. J. (2015). Current topics in active and intelligent food packaging for preservation of fresh foods. J. Sci. Food Agric. 95, 2799-2810. doi: 10.1002/jsfa.7218

Li, J.-H., Miao, J., Wu, J.-L., Chen, S.-F., and Zhang, Q.-Q. (2014). Preparation and characterization of active gelatin-based films incorporated with natural antioxidants. Food Hydrocoll. 37, 166-173. doi: 10.1016/j.foodhyd.2013.10.015

Liu, Y., Gao, W., Zhang, C., Tang, P., Zhao, Y., and Wu, D. (2017). Sequential molecule-triggered-release system based on acetylated amylose helix aggregates. Chem. Commun. 53, 10680-10683. doi: 10.1039/C7CC05783K

López, P., Sánchez, C., Batlle, R., and Nerín, C. (2007). Development of flexible antimicrobial films using essential oils as active agents. J. Agric. Food Chem. 55, 8814-8824. doi: 10.1021/jf071737b

López-de-Dicastillo, C., Alonso, J. M., Catalá, R., Gavara, R., and HernándezMuñoz, P. (2010). Improving the Antioxidant protection of packaged food by incorporating natural flavonoids into ethylene-vinyl alcohol copolymer (EVOH) films. J. Agric. Food Chem. 58, 10958-10964. doi: 10.1021/jf1022324

López-de-Dicastillo, C., Gómez-Estaca, J., Catal,á, R., Gavara, R., and HernándezMuñoz, P. (2012). Active antioxidant packaging films: development and effect on lipid stability of brined sardines. Food Chem. 131, 1376-1384. doi: $10.1016 /$ j.foodchem.2011.10.002

Ludueña, L. N., Fortunati, E., Morán, J. I., Alvarez, V. A., Cyras, V. P., Puglia, D., et al. (2015). Preparation and characterization of polybutylenesuccinate/poly(ethylene-glycol)/cellulose nanocrystals ternary composites. J. Appl. Polym. Sci. 133:15. doi: 10.1002/app.43302

Luzi, F., Fortunati, E., Di Michele, A., Pannucci, E., Botticella, E., Santi, L., et al. (2018a). Nanostructured starch combined with hydroxytyrosol in poly(vinyl alcohol) based ternary films as active packaging system. Carbohydr. Polym. 193, 239-248. doi: 10.1016/j.carbpol.2018.03.079

Luzi, F., Fortunati, E., Giovanale, G., Mazzaglia, A., Torre, L., and Balestra, G. M. (2017). Cellulose nanocrystals from Actinidia deliciosa pruning residues combined with carvacrol in PVA_CH films with antioxidant/antimicrobial properties for packaging applications. Int. J. Biol. Macromol. 104, 43-55. doi: 10.1016/j.ijbiomac.2017.05.176

Luzi, F., Puglia, D., Dominici, F., Fortunati, E., Giovanale, G., Balestra, G. M., et al. (2018b). Effect of gallic acid and umbelliferone on thermal, mechanical, antioxidant and antimicrobial properties of poly (vinyl alcohol-co-ethylene) films. Polym. Degrad. Stab. 152, 162-176. doi: 10.1016/j.polymdegradstab.2018.04.015

Martínez-Abad, A., Ocio, M. J., and Lagaron, J. M. (2014). Morphology, physical properties, silver release, and antimicrobial capacity of ionic silver-loaded poly(l-lactide) films of interest in food-coating applications. J. Appl. Polym. Sci. 131:21. doi: 10.1002/app.41001

Masek, A. (2015). Flavonoids as natural stabilizers and color indicators of ageing for polymeric materials. Polymers 7, 1125-1144. doi: 10.3390/polym7061125

Mazimba, O. (2017). Umbelliferone: sources, chemistry and bioactivities review. Bull. Facul. Pharm. Cairo Univ.55, 223-232. doi: 10.1016/j.bfopcu.2017. 05.001

Muller, J., González-Martínez, C., and Chiralt, A. (2017). Poly(lactic) acid (PLA) and starch bilayer films, containing cinnamaldehyde, obtained by compression moulding. Eur. Polym. J. 95, 56-70. doi: 10.1016/j.eurpolymj.2017.07.019

Murthy, P. S., and Naidu, M. M. (2012). Recovery of phenolic antioxidants and functional compounds from coffee industry by-products. Food Bioprocess Technol. 5, 897-903. doi: 10.1007/s11947-010-0363-z

Nair, S. S., Sharma, S., Pu, Y., Sun, Q., Pan, S., Zhu, J. Y., et al. (2014). High shear homogenization of lignin to nanolignin and thermal stability of nanolignin-polyvinyl alcohol blends. ChemSusChem 7, 3513-3520. doi: $10.1002 /$ cssc. 201402314

Pagno, C. H., de Farias, Y. B., Costa, T. M. H., de Oliveira Rios, A., and Flôres, S. H. (2016). Synthesis of biodegradable films with antioxidant properties based on cassava starch containing bixin nanocapsules. J. Food Sci. Technol. 53, 3197-3205. doi: 10.1007/s13197-016-2294-9
Peelman, N., Ragaert, P., De Meulenaer, B., Adons, D., Peeters, R., Cardon, L., et al. (2013). Application of bioplastics for food packaging. Trends Food Sci. Technol. 32, 128-141. doi: 10.1016/j.tifs.2013.06.003

Piñeros-Hernandez, D., Medina-Jaramillo, C., López-Córdoba, A., and Goyanes, S. (2017). Edible cassava starch films carrying rosemary antioxidant extracts for potential use as active food packaging. Food Hydrocoll. 63, 488-495. doi: 10.1016/j.foodhyd.2016.09.034

Pracella, M., Haque, M. M.-U., and Puglia, D. (2014). Morphology and properties tuning of PLA/cellulose nanocrystals bio-nanocomposites by means of reactive functionalization and blending with PVAc. Polymer 55, 3720-3728. doi: 10.1016/j.polymer.2014.06.071

Requena, R., Jiménez, A., Vargas, M., and Chiralt, A. (2016). Poly [(3hydroxybutyrate)-co-(3-hydroxyvalerate)] active bilayer films obtained by compression moulding and applying essential oils at the interface. Polym. Int. 65, 883-891. doi: 10.1002/pi.5091

Rexali, A. (2007). FTIR and FT-raman spectral investigation of 7-hydroxycoumarin. Cauvery Res. J. 1, 75-78.

Richter, A. P., Brown, J. S., Bharti, B., Wang, A., Gangwal, S., Houck, K., et al. (2015). An environmentally benign antimicrobial nanoparticle based on a silver-infused lignin core. Nat. Nanotechnol. 10:817. doi: 10.1038/nnano.2015.141

Scaffaro, R., and Lopresti, F. (2018). Processing, structure, property relationships and release kinetics of electrospun PLA/Carvacrol membranes. Eur. Polym. J. 100, 165-171. doi: 10.1016/j.eurpolymj.2018.01.035

Scaffaro, R., Lopresti, F., Botta, L., and Maio, A. (2016). Mechanical behavior of polylactic acid/polycaprolactone porous layered functional composites. Composit. B Eng. 98, 70-77. doi: 10.1016/j.compositesb.2016.05.023

Seoane, I. T., Cerrutti, P., Vázquez, A., Manfredi, L. B., and Cyras, V. P. (2017). Polyhydroxybutyrate-based nanocomposites with cellulose nanocrystals and bacterial cellulose. J. Polym. Environ. 25, 586-598. doi: 10.1007/s10924-016-0838-8

Wang, C., Xiong, Y., Fan, B., Yao, Q., Wang, H., Jin, C., et al. (2016). Cellulose as an adhesion agent for the synthesis of lignin aerogel with strong mechanical performance, Sound-absorption and thermal Insulation. Sci. Rep. 6:32383. doi: $10.1038 /$ srep 32383

Yang, H., Wang, J., Yang, F., Chen, M., Zhou, D., and Li, L. (2016a). Active packaging films from ethylene vinyl alcohol copolymer and clove essential oil as shelf life extenders for grass carp slice. Pack. Technol. Sci. 29, 383-396. doi: $10.1002 /$ pts.2215

Yang, W., Fortunati, E., Bertoglio, F., Owczarek, J. S., Bruni, G., Kozanecki, M., et al. (2018). Polyvinyl alcohol/chitosan hydrogels with enhanced antioxidant and antibacterial properties induced by lignin nanoparticles. Carbohydr. Polym. 181, 275-284. doi: 10.1016/j.carbpol.2017.10.084

Yang, W., Fortunati, E., Dominici, F., Giovanale, G., Mazzaglia, A., Balestra, G. M., et al. (2016b). Synergic effect of cellulose and lignin nanostructures in PLA based systems for food antibacterial packaging. Eur. Polym. J. 79, 1-12. doi: 10.1016/j.eurpolymj.2016.04.003

Yang, W., Fortunati, E., Dominici, F., Kenny, J. M., and Puglia, D. (2015a). Effect of processing conditions and lignin content on thermal, mechanical and degradative behavior of lignin nanoparticles/polylactic (acid) bionanocomposites prepared by melt extrusion and solvent casting. Eur. Polym. J. 71, 126-139. doi: 10.1016/j.eurpolymj.2015.07.051

Yang, W., Kenny, J. M., and Puglia, D. (2015b). Structure and properties of biodegradable wheat gluten bionanocomposites containing lignin nanoparticles. Ind. Crops Prod. 74, 348-356. doi: 10.1016/j.indcrop.2015.05.032

Conflict of Interest Statement: The authors declare that the research was conducted in the absence of any commercial or financial relationships that could be construed as a potential conflict of interest.

Copyright ๑ 2019 Iglesias Montes, Luzi, Dominici, Torre, Cyras, Manfredi and Puglia. This is an open-access article distributed under the terms of the Creative Commons Attribution License (CC BY). The use, distribution or reproduction in other forums is permitted, provided the original author(s) and the copyright owner(s) are credited and that the original publication in this journal is cited, in accordance with accepted academic practice. No use, distribution or reproduction is permitted which does not comply with these terms. 